\title{
No Serologic Evidence of Middle East Respiratory Syndrome Coronavirus Infection among Camel Farmers Exposed to Highly Seropositive Camel Herds: A Household Linked Study, Kenya, 2013
}

\author{
Peninah Munyua, ${ }^{1 \star} \dagger$ Victor Max Corman, ${ }^{2,3} \dagger$ Austine Bitek, ${ }^{4}$ Eric Osoro, ${ }^{5}$ Benjamin Meyer, ${ }^{2}$ Marcel A. Müller, ${ }^{2}$ Erik Lattwein, ${ }^{6}$ \\ S. M. Thumbi, ${ }^{7,8}$ Rees Murithi, ${ }^{4}$ Marc-Alain Widdowson, ${ }^{1}$ Christian Drosten, ${ }^{2,3}$ and M. Kariuki Njenga ${ }^{7,8}$ \\ ${ }^{1}$ Global Disease Detection Program, Division of Global Health Protection, U.S. Centers for Disease Control and Prevention, Nairobi, Kenya; \\ ${ }^{2}$ Institute of Virology, University of Bonn Medical Centre, Bonn, Germany; ${ }^{3}$ German Centre for Infection Research, Partner Site Bonn-Cologne, \\ Bonn, Germany; ${ }^{4}$ State Department of Veterinary Services; Ministry of Agriculture Livestock and Fisheries, Nairobi, Kenya; ${ }^{5}$ Department of \\ Preventive and Promotive Health, Ministry of Health, Nairobi, Kenya; ${ }^{6}$ EUROIMMUN AG, Lübeck, Germany; ${ }^{7}$ Center for Global Health \\ Research, Kenya Medical Research Institute, Nairobi, Kenya; ${ }^{8}$ Paul G. Allen School for Global Animal Health,
} Washington State University, Pullman, Washington

\begin{abstract}
High seroprevalence of Middle East respiratory syndrome coronavirus (MERS-CoV) among camels has been reported in Kenya and other countries in Africa. To date, the only report of MERS-CoV seropositivity among humans in Kenya is of two livestock keepers with no known contact with camels. We assessed whether persons exposed to seropositive camels at household level had serological evidence of infection. In 2013,760 human and 879 camel sera were collected from 275 and 85 households respectively in Marsabit County. Data on human and animal demographics and type of contact with camels were collected. Human and camel sera were tested for antiMERS-CoV lgG using a commercial enzyme-linked immunosorbent assay (ELISA) test. Human samples were confirmed by plaque reduction neutralization test (PRNT). Logistic regression was used to identify factors associated with seropositivity. The median age of persons sampled was 30 years (range: 5-90) and 50\% were males. A quarter (197/ 760) of the participants reported having had contact with camels defined as milking, feeding, watering, slaughtering, or herding. Of the human sera, 18 (2.4\%) were positive on ELISA but negative by PRNT. Of the camel sera, 791 (90\%) were positive on ELISA. On univariate analysis, higher prevalence was observed in female and older camels over 4 years of age $(P<0.05)$. On multivariate analysis, only age remained significantly associated with increased odds of seropositivity. Despite high seroprevalence among camels, there was no serological confirmation of MERS-CoV infection among camel pastoralists in Marsabit County. The high seropositivity suggests that MERS-CoV or other closely related virus continues to circulate in camels and highlights ongoing potential for animal-to-human transmission.
\end{abstract}

\section{INTRODUCTION}

In September 2012, Middle East respiratory syndrome coronavirus (MERS-CoV) was first detected in humans, and as of June 2016, 1,733 laboratory-confirmed human cases and 628 deaths had been reported to the World health Organization (WHO) from 27 countries. ${ }^{1}$ The majority of the cases have been reported from Arabian Peninsula, but cases imported to other countries have caused large hospitallinked outbreaks, such as in South Korea, in $2015 .^{1}$ Severe respiratory disease and death rate is higher in infections among older patients and those with preexisting conditions. ${ }^{2-4}$ Dromedary camels have been identified as a potential reservoir for the virus after detection of virus in camels in Saudi Arabia, Oman, and Qatar, ${ }^{5-7}$ and of a high level of seroprevalence of MERS-CoV antibodies in camel populations from a wider range of countries including countries in the Middle East and Africa. ${ }^{8-14}$ Notably, however, Australia has documented absence of MERS-CoV antibodies among camels. ${ }^{15,16}$ Most MERS-CoV infections in humans are not linked to camel exposure and are thought to be due to human-to-human transmission particularly in health-care settings. The low frequency of camel-to-human infections is supported by the finding that MERS-CoV seroprevalence among the general human population in Saudi Arabia is less

*Address correspondence to Peninah Munyua, Global Disease Detection Program, Division of Global Health Protection, U.S. Centers for Disease Control and Prevention, P.O. Box 606-00627, Nairobi, Kenya. E-mail: ikg2@cdc.gov

†These authors contributed equally to this work. than $0.5 \%$, though significantly higher in camel shepherds (2.3\%) and slaughterhouse workers (3.6\%). ${ }^{17}$

According to the Food and Agriculture Organization, the world population of camels in 2001 was 19 million camels, of which, 17 million were dromedary camels and approximately $65 \%$ of these were found in the eastern African countries of Sudan, Somalia, Ethiopia, and Kenya. ${ }^{18}$ Despite the fact that the majority of dromedary camels are in Africa, no case of MERS-CoV in humans has been reported in Africa, except for a cluster of three family members in Tunisia, in 2013, associated with an imported index case and no history of exposure to camels. ${ }^{19}$ A retrospective study carried out in Kenya detected MERS-CoV antibodies in more than $90 \%$ of camels from various parts of the country. ${ }^{8}$ A recent study that analyzed $>1,000$ human sera from among pastoralists who did not keep camels reported two likely asymptomatic humans $(<0.2 \%)$ positive for MERSCoV neutralizing antibodies. ${ }^{20}$

To understand the risk of transmission between camels and humans living in close contact, we conducted a serosurvey in camels and humans in same households to determine the prevalence of MERS-CoV antibodies among pastoral communities in northern Kenya that live in close association with camels and investigated risk factors associated with seropositivity in camels and humans.

\section{METHODS}

Study site and design. In 2013, we conducted a crosssectional serosurvey of humans and camels in Marsabit County, ${ }^{21}$ using a two-stage random sampling methodology. 
First, $10 \%(N=10)$ of sublocations (the smallest official administrative unit in the county) were randomly selected representing pastoral, agropastoral, and periurban livestock production systems, then households were randomly selected (weighted by sublocation human population) from each sublocation through random geographical coordinates generated using ArcGIS as previously described. ${ }^{21}$ Households were enrolled irrespective of animal ownership, and in each household, a maximum of three persons over 5 years of age were randomly selected and enrolled after providing informed consent. Random selection of camels was attempted and sampling was based on herd size: all camels in households with < 15 camels were sampled and up to 15 camels in households with larger herd sizes.

Sample collection and transportation. A $5-\mathrm{mL}$ venous blood sample was collected from enrolled persons and a structured questionnaire was administered to collect information on individual factors such as demographics, medical history, animal ownership, and exposure to animals and animal products, as well as household risk factors such as socioeconomic status and size of household. Contact with camels was defined as milking, feeding, watering, slaughtering, or herding camels and for those who reported contact, the frequency for each type of contact was recorded. Blood samples were obtained from selected camels from the jugular vein. Serum samples were obtained daily after centrifugation of coagulated blood sample at 3,000 $\times g$ for 15 minutes at the nearest health center at the end of each day, stored at $-20^{\circ} \mathrm{C}$, and later shipped in dry ice for storage at $-20^{\circ} \mathrm{C}$ at the Kenya Medical Research Institute (KEMRI)/ Centers for Disease Control and Prevention (CDC) laboratory in Kisumu (human samples) and the Central Veterinary Laboratory in Nairobi (camel samples). Sera were subsequently thawed, aliquoted, and one aliquot was shipped to the University of Bonn, Germany, on dry ice for MERS-CoV antibody testing. On arrival, samples were stored at $-80^{\circ} \mathrm{C}$ before testing.

Serological testing. Before conducting serological analysis, all serum samples were heat inactivated at $56^{\circ} \mathrm{C}$ for 30 minutes. For the human sera, a two-step approach recommended by the WHO for the detection of antibodies against MERS-CoV was used. ${ }^{22}$ In a first step, screening for antiMERS-CoV IgG was carried out using a commercial enzymelinked immunosorbent assay (ELISA) kit (EUROIMMUN AG, Lübeck, Germany). In a second step, all ELISA-positive sera were tested for MERS-CoV neutralizing antibodies by plaque reduction neutralization test (PRNT) for confirmation. For the ELISA test, all human sera were tested at 1:100 dilution and an optical density ratio of 0.3 used as cutoff. ${ }^{23}$ For PRNT, serial dilutions of sera starting with a 1:10 dilution were incubated with the virus. The serum dilution resulting in at least $50 \%$ plaque reduction (PRNT50) was recorded. The 1:20 dilution was ranked as the lowest possible diagnostically significant titer as evaluated previously. ${ }^{23,24}$

For the camel sera, the anti-MERS-CoV ELISA Camel IgG ELISA kit was used at a sera dilution of 1:100 (EUROIMMUN AG) as described previously. ${ }^{8,10,11}$ An optical density ratio of 0.4 was used as cutoff as exhaustively evaluated in several studies before, including investigation of camels sampled at the same geographic region in Africa. 8,10,11

Data analysis. All analyses were done using STATA 12 (Stata Corporation, College Station, TX). MERS-CoV sero- positivity in humans was defined as specimens that tested positive to MERS-CoV by PRNT, whereas in camels it was defined as sera that tested positive by ELISA. To account for clustering, the study design strata (livestock production systems) were specified and the primary (sublocation) and secondary (household) sampling units were defined. All analyses were subsequently carried out while accounting for clustering by applying the prefix svy in Stata 12. Overall seroprevalence was determined and thereafter seropositivity was determined for each herd and by sublocation. Analysis of variance was used to compare differences in seroprevalence by sublocation.

Univariate analysis was conducted at animal population and herd levels. The animal population level analysis used the MERS-CoV serostatus as response variable and animallevel factors (age and sex) and herd-level explanatory variables (e.g., herd size of different livestock species, having bought or sold animals) as covariates. Univariate analysis was conducted for explanatory variables and those with a $P$ value $<0.2$ were taken into the multivariate logistic regression model. Multivariate logistic regression was used to identify factors associated with MERS-CoV seropositivity at herd level while controlling for other covariates.

Ethical clearance. Ethical clearance and approval were obtained from the KEMRI Scientific Ethical Review committee, the CDC Institutional Review Board, and the Ministry of Agriculture Livestock and Fisheries for additional testing of archived sera. Permits for the import of camel sera into Europe were given by the responsible German authority.

\section{RESULTS}

Human. A total of 760 persons distributed in 275 households in 10 sublocations were sampled. Of the 275 households, 85 (30.9\%) owned camels. The median age was 30 years (range: $5-90$ ); $50 \%$ were males and $50 \%$ were farmers or worked on the farm (Table 1).

TABLE 1

Household and demographic characteristics of persons tested for exposure to Middle East respiratory syndrome coronavirus, Kenya $2013(N=760)$

\begin{tabular}{lc}
\hline \multicolumn{1}{c}{ Household characteristics } & Number (\%) \\
\hline Number of households & 275 \\
Number of households owning camels (\%) & $85(30.9)$ \\
Camels owned per household; median (range) & $20(1,50)$ \\
Individual characteristics & \\
Number of individuals & 760 \\
Sex: male number (\%) & $382(50.3)$ \\
Age: median (range) & $30(5-90)$ \\
Mean (standard deviation) & $34.3(19.8)$ \\
Education level completed & \\
Postsecondary/secondary & $52(6.8)$ \\
Primary/preprimary & $194(25.5)$ \\
No education & $514(67.6)$ \\
Occupation & \\
Works on farm/farmer & $379(49.9)$ \\
Salaried, off farm, skilled & $42(5.5)$ \\
Housewife & $58(7.6)$ \\
Salaried, off farm, unskilled & $90(11.8)$ \\
Student & $174(22.9)$ \\
Other & $17(2.2)$ \\
\hline
\end{tabular}


Of the 760 sera tested by ELISA, 18 (2.4\%) were positive, and all were from different households (Figure 1). None of these 18 sera were confirmed for MERS-CoV by PRNT.

Human exposure to camels. A total of 197/760 (25.9\%) of the participants reported having had contact with camels in the last year. Of these, $40 \%$ and $30 \%$ reported daily milking and herding camels, respectively. A quarter of the participants reported daily consumption of unboiled camel milk (Table 2).

Camel. Prevalence by herd and sublocation. Camel samples were drawn from 85 herds distributed in eight of 10 sublocations (Figure 2). None of the selected households in two sublocations (Gurumesa and Dambala Fachana) owned camels and hence no camels were available for sampling in two sublocations (Figure 2). In camels, the overall seroprevalence of MERS-CoV antibodies by ELISA test in the sampled population was $90 \%$ (95\% confidence interval $[\mathrm{Cl}]=88-92)$ (Figure 1). At least one camel tested positive in each of the 85 herds and in 59\% (50/85) of the herds all camels tested positive. The lowest seroprevalence by herd was $26.7 \%$ $(95 \% \mathrm{Cl}=7.8-55.1)$. Seroprevalence by sublocation was highest at $100 \%$ in Majengo sublocation and lowest in Rukesa Qarsa sublocation at $69.6 \%$. Herd seropositivity varied significantly by sampling sublocation $\left(F_{(7,77)}=5.73, P<0.001\right)$.

Risk factors for camel seropositivity to MERS-CoV. On univariate analysis, significantly higher prevalence was observed in female camels $\left(93 \% ; x^{2}=23.9, P<0.05\right)$ compared with male camels (81\%) and in camels 4 years of age or older compared with those camels less than 4 years of age $\left(x^{2}=129, P<0.05\right)$ (Table 3$)$. Also, the total number of cattle in the camel herd was significantly associated with marginally decreased odds of MERS-CoV seropositivity. Of the 85 camel-owning herds, 74 (87\%) owned at least one other livestock of cattle, sheep, and goats. On multivariate analysis, only age remained significantly associated with increased odds of being seropositive to MERS-CoV.

\section{DISCUSSION}

We found that all camel herds in Marsabit showed evidence of past MERS-CoV infection and $90 \%$ of all camels in our study tested positive for MERS-CoV antibodies. However, none of the 760 persons that lived in close association with these camels tested positive for MERS-CoV neutralizing antibodies. Our sampled human population had very close interactions with their camels, including consumption of unpasteurized milk and meat, and direct handling of the animals during routine husbandry practices such as milking, herding, slaughtering, and assisting with births. These camel-human interactions provided ample opportunities for human contact with camels and their products such as meat, milk, nasal secretions, and feces

A

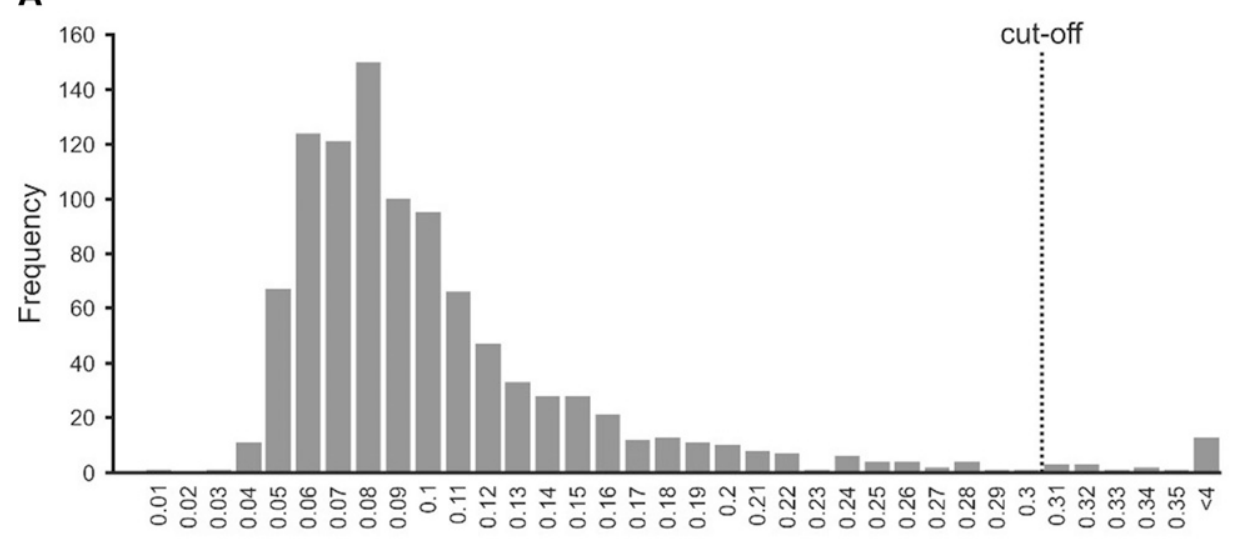

B

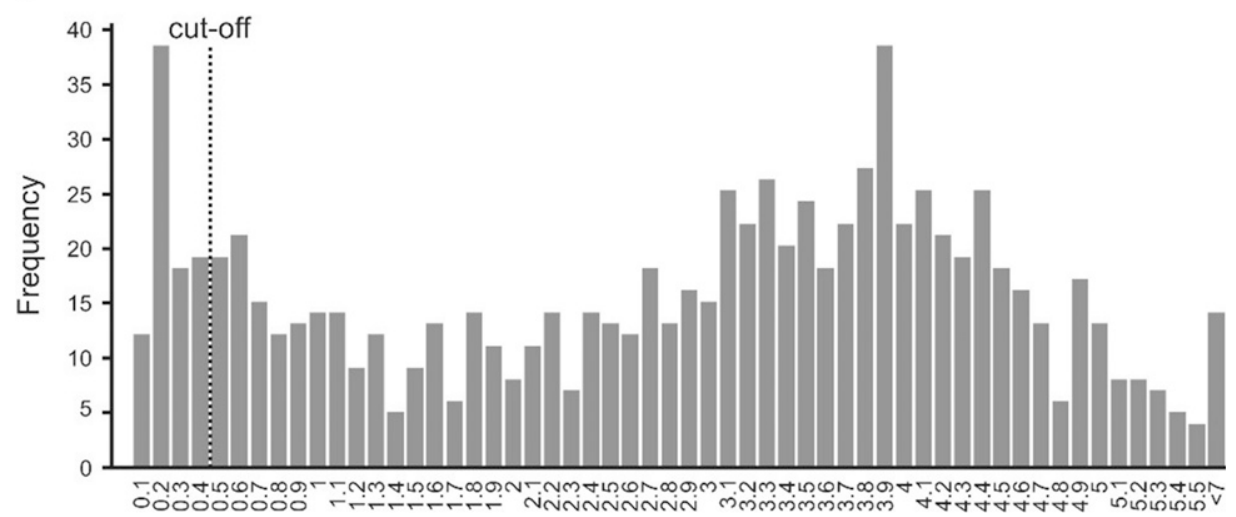

FIGURE 1. Frequency distribution plot. Frequency of all Middle East respiratory syndrome coronavirus (MERS-CoV) IgG enzyme-linked immunosorbent assay (ELISA) optical density (OD) ratios grouped in classes of 0.01 for human samples (A) and 0.1 for dromedary camel samples (B). The vertical dashed lines represent the ELISA cutoff value as determined in several studies before. The values given on the $x$ axis represent the upper bound of the corresponding class. 
TABLE 2

Characteristics of contact with camels of persons tested for exposure to Middle East respiratory syndrome coronavirus from Marsabit, Kenya 2013

\begin{tabular}{|c|c|c|}
\hline & & No. (\%) \\
\hline Characteristic & Response & $N=197$ \\
\hline $\begin{array}{l}\text { Contact (milk, feed, water, } \\
\text { slaughter, or herd) } \\
\text { with camels }\end{array}$ & Yes & $197 / 760(26)$ \\
\hline \multirow{4}{*}{$\begin{array}{l}\text { Frequency of } \\
\text { feeding/watering camels }\end{array}$} & Daily & $43(22)$ \\
\hline & Several times a month & $100(51)$ \\
\hline & Rarely & 27 (14) \\
\hline & Never & $27(14)$ \\
\hline \multirow[t]{4}{*}{ Frequency of milking camels } & Daily & $78(40)$ \\
\hline & Several times a month & $46(23)$ \\
\hline & Rarely & $20(10)$ \\
\hline & Never & $53(27)$ \\
\hline \multirow{4}{*}{$\begin{array}{l}\text { Frequency of slaughtering } \\
\text { or handling meat camels }\end{array}$} & Daily & $17(9)$ \\
\hline & Several times a month & $14(7)$ \\
\hline & Rarely & $64(32)$ \\
\hline & Never & $102(52)$ \\
\hline \multirow[t]{4}{*}{ Frequency of herding camels } & Daily & 59 (30) \\
\hline & Several times a month & $76(39)$ \\
\hline & Rarely & $32(16)$ \\
\hline & Never & $30(15)$ \\
\hline \multirow{3}{*}{$\begin{array}{l}\text { Frequency of assistance } \\
\text { with births in camels }\end{array}$} & Sometimes & $79(40)$ \\
\hline & Rarely & 38 (19) \\
\hline & Never & $80(41)$ \\
\hline \multirow{3}{*}{$\begin{array}{l}\text { Frequency of consumption } \\
\text { of unboiled camel milk } \\
(N=706)\end{array}$} & Daily & $180(25)$ \\
\hline & Occasionally & $254(36)$ \\
\hline & Never & $272(38)$ \\
\hline \multirow{3}{*}{$\begin{array}{l}\text { Frequency of consumption } \\
\text { of boiled camel milk }\end{array}$} & Daily & $51(7)$ \\
\hline & Occasionally & $137(19)$ \\
\hline & Never & $518(73)$ \\
\hline
\end{tabular}

from camels, all of which are potential transmission pathways for the virus. ${ }^{6,25,26}$ Yet, none of these exposed persons tested positive for MERS-CoV neutralizing antibodies that are specific for MERS-CoV infection. Our findings suggest no camel-to-human transmission of MERS-CoV in the area at the time of the study.

However, though we found no evidence of infection in this human population exposed to camels, a serosurvey of approximately 1,000 individuals in Kenya found two seropositive individuals among Kenyan pastoralists, confirmed by PRNT, but neither had reported contact with camels nor travel history and keeping camels was uncommon among pastoralist in the region, suggesting the exposures could have been unrelated to contact with camels. ${ }^{20}$ It is also possible that the MERS-CoV circulating in Kenya, may be antigenically different from the Middle Eastderived virus used in the PRNT in both studies, rendering the PRNT test less sensitive. Furthermore, the lack of detectable neutralizing antibodies in humans in our study could also have been due to the possibility of short life span of anti-MERS-CoV antibodies in humans, as suggested in a recent study. ${ }^{27}$

However, the high seroprevalence among the younger camels in our study (73\%) suggests continuous and recent circulation of MERS-CoV in camel herds in Kenya and pos- sible risk of transmission to humans that have frequent direct contact to them. In Saudi Arabia, persons with occupational exposures to camels were found to be at a significantly increased risk of up to 23 times of being seropositive. ${ }^{17}$ Although camel-to-human transmission occurs infrequently in the Arabian Peninsula, and possibly in other regions of Kenya, ${ }^{20}$ the lack of evidence of any previous exposure to MERS-CoV among the pastoralist community was unexpected. Despite the study being in a camel pastoralist region, only $30 \%$ of the households owned camels and $26 \%$ of the participants reported direct contact with camels. Given that virus shedding in camels may be seasonal and associated with the reproduction cycle ${ }^{28}$ and the potentially waning immunity in subclinical human infections, ${ }^{27}$ it is possible that the sample size was not sufficient and the study period provided a limited opportunity to detect previous infections to make conclusive statement on exposure status among humans in Kenya. In addition, the camels were not evaluated from active infection status or compatible clinical presentation. However, given our sample size, this study suggests that among all camel pastoralists the true seroprevalence is lower than $0.4 \%$ at $97.5 \%$ confidence level (Binomial exact one-sided $\mathrm{Cl}$ ). In addition, considering that the sampled persons represents a population with high exposure to camels, the continued lack of reported human cases in Africa despite evidence of high and widespread exposure of dromedary camels to MERS-CoV or other related viruses presents a pertinent question on the epidemiology of the disease in different ecologies.

The MERS-CoV circulating in the camels in Kenya has not been isolated or sequenced, but it seems possible that virus strains circulating in camels in the Middle East and in Africa might differ in their ability to efficiently transmit from camels to humans. Possible reasons for lack of camel-tohuman transmission in our study region compared with the Arabian Peninsula might be different characteristics of the circulating virus strains itself. Such virus-intrinsic factors which could alter zoonotic transmission rates might include different phenotypes, pathogenicity, and the ability to survive in the environment. The differences in the environmental conditions in Kenya compared with the Arabian Peninsula might also explain the differences in the rate of camel-to-human transmission events. Of note, an ecological study that compared the environmental conditions under which camel-to-human cases occur with those of the broader population of all human MERS-CoV cases suggested that better camel-to-human virus transmission occurs under a narrow set of environmental conditions. ${ }^{29}$ Such conditions could be absent in Marsabit County, hence limited virus transmission from camels to humans.

Some of the hypotheses presented to explain the apparent disparity between camel-to-human transmission in the Middle East and Africa include different risk profiles related to different camel farming systems. In the Middle East, camel farming is mostly semi-intensive and intensive system where camels are housed and stall fed to maximize productivity for meat and milk as opposed to most of Africa where camel farming is mainly extensive and camels roam over extensive areas in search of pasture and water. ${ }^{30}$ The intensive farming characterized by livestock sheds could present greater opportunity for virus survival and transmission from camels to humans. 


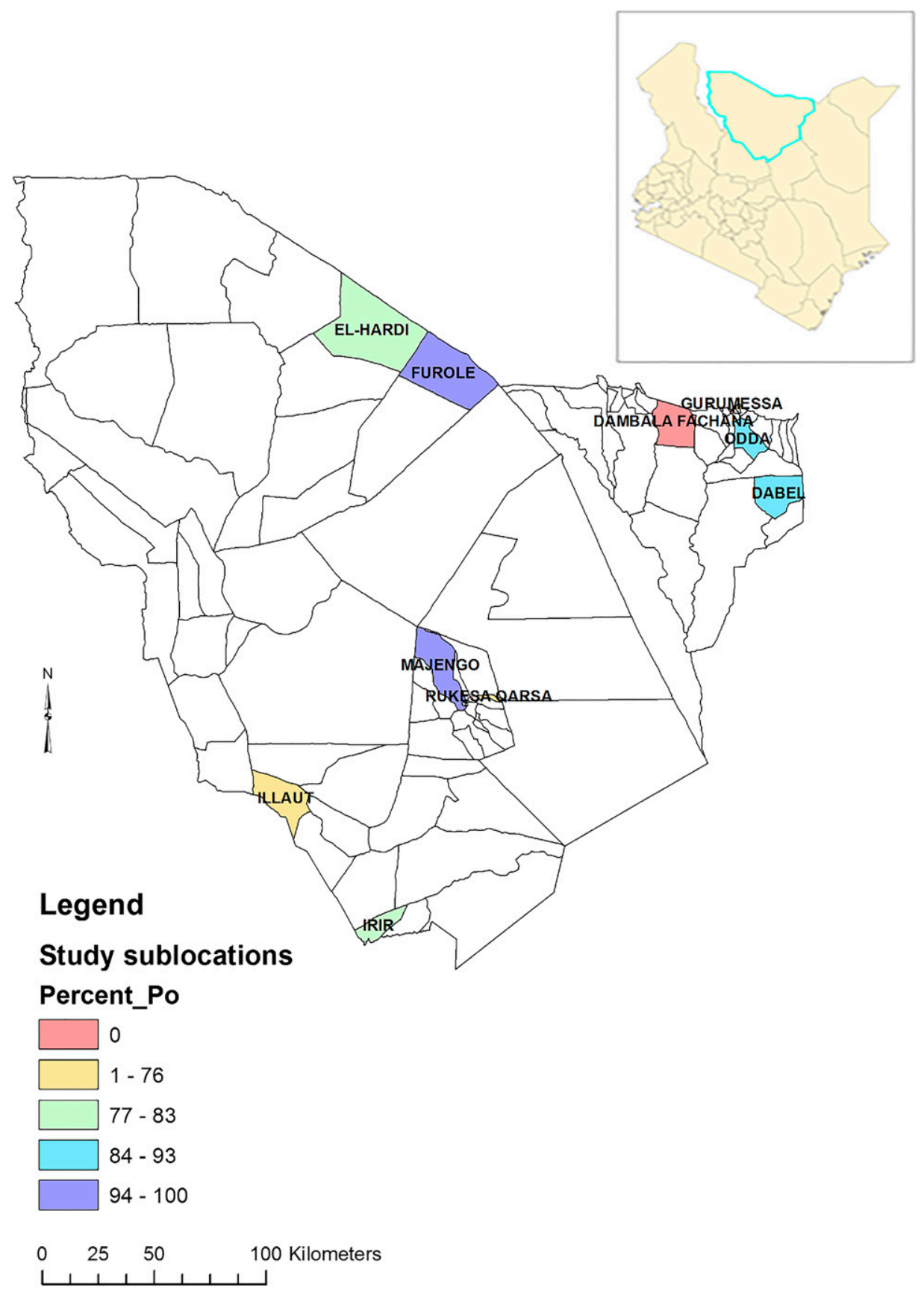

FIGURE 2. Map of Marsabit County showing seroprevalence of Middle East respiratory syndrome coronavirus (MERS-CoV) in camels by sublocations. Inset is a map of Kenya showing county boundaries.

This study characterizes the local practices of this pastoralist community in reference to camels and highlights the extensive direct contact of the people with camels in natural settings that could facilitate transmission of virus from camels to humans. Studies focusing on humans with occupational exposure to camels in Africa where MERS$\mathrm{COV}$ in camels has been reported but no human cases are key in elucidating the ecology of the virus in this region. This study suggests likely reduced transmissibility of the MERS-COV from camels to humans in Kenya compared with similarly occupationally exposed persons in Saudi Arabia though the mechanism is unclear. Longitudinal stud- ies among the camel pastoralist communities to explore possibility of mild infections associated with waning immunity to MERS-COV, coupled with studies focusing on finding the virus in camel herds and characterization of MERS-CoV strains in camels in Kenya to compare with strains from Middle East and elsewhere is an important gap. In addition, enhanced surveillance of MERS-CoV in human populations especially in camel-raising areas, and increased vigilance in hospitals for all unusual cases of severe respiratory disease, especially among persons who have traveled internationally to areas with active virus transmission is key with prepared in-hospital infection control plans to 
TABLE 3

Univariate analysis of factors associated with camel Middle East respiratory syndrome coronavirus seropositivity in Marsabit, 2013

\begin{tabular}{|c|c|c|c|c|}
\hline & Total (\%) & Number positive (\%) & Crude odds ratio & $P$ value \\
\hline \multicolumn{5}{|l|}{ Individual characteristics } \\
\hline \multicolumn{5}{|l|}{ Sex } \\
\hline Female & $664(76)$ & $616(93)$ & Reference & NA \\
\hline Male & $213(24)$ & $173(81)$ & $0.3(0.2,0.5)$ & $0.01^{\star}$ \\
\hline \multicolumn{5}{|l|}{ Age (years) } \\
\hline $1-4$ & $285(32)$ & $209(73)$ & Reference & \\
\hline $4-6$ & 116 (13) & $114(98)$ & $20.7(5.4,78.8)$ & NA \\
\hline$>6$ & $476(54)$ & $466(98)$ & $16.9(7.6,37.7)$ & $<0.01^{*}$ \\
\hline \multicolumn{5}{|l|}{ Household characteristics } \\
\hline \multicolumn{5}{|l|}{ HHs keeping other livestock on the farm? } \\
\hline No & $123(14)$ & $116(94)$ & Reference & NA \\
\hline Yes & $756(86)$ & 676 (89) & $0.5(0.2,0.9)$ & 0.30 \\
\hline Total number of cattle in the camel herd & & & $0.98 t$ & $0.02^{*}$ \\
\hline Total number of sheep in the camel herd & & & $0.99 \dagger$ & 0.94 \\
\hline Total number of goats in the camel herd & & & $0.99 \dagger$ & 0.51 \\
\hline Number of other livestock owned by $\mathrm{HH}$ & _- & _ & $0.9+$ & 0.38 \\
\hline \multicolumn{5}{|l|}{ Acquired animals into farm in the last 1 year } \\
\hline No & $668(79)$ & $606(91)$ & Reference & NA \\
\hline Yes & $179(21)$ & $156(87)$ & $0.7(0.3,1.8)$ & 0.34 \\
\hline \multicolumn{5}{|l|}{ Sold livestock from farm in the last 1 year } \\
\hline No & $296(35)$ & $282(95)$ & Reference & NA \\
\hline Yes & $548(65)$ & $477(87)$ & $0.3(0.2,0.7)$ & 0.12 \\
\hline \multicolumn{5}{|l|}{ Livestock production system } \\
\hline Agropastoralistł & $14(2)$ & $10(71)$ & Reference & NA \\
\hline Nomadic pastoralist§ & $771(98)$ & $698(90)$ & 3.8 & 0.11 \\
\hline \multicolumn{5}{|l|}{ Reported exposure to wildlife } \\
\hline No & $471(56)$ & $424(90)$ & Reference & NA \\
\hline Yes & $376(44)$ & $338(90)$ & $0.9(0.5,2.1)$ & 0.98 \\
\hline
\end{tabular}

$\mathrm{HH}=$ household.

*Statistically significant $P$ value.

†The number of animals (cattle, sheep, goats, or total) owned by the household was used as a continuous variable.

$\ddagger$ Pastoralists with regular back-and-forth livestock movements between relatively fixed locations.

$\S$ Pastoralist with high mobility and in irregular patterns.

prevent rapid nosocomial transmission of MERS-CoV as previously seen.

Received November 8, 2016. Accepted for publication January 30, 2017.

Published online March 20, 2017.

Acknowledgment: We thank the Kenya Ministry of Health, Ministry of Agriculture, Livestock and Fisheries, the County Government of Marsabit, and Kenya Medical Research Institute (KEMRI) for their participation in the implementation of the study. Clayton Onyango from the Diagnostic and Laboratory Systems program of the Division of Global health protection, CDC-Kenya, Fredrick Ade and Dennis Odhiambo from KEMRI for their support in the processing and shipment of specimens to Europe.

Financial support: Financial support for the field work was provided by the U.S. Department of Defense's Defense Threat Reduction Agency and U.S. Centers for Disease Control and Prevention. All the laboratory testing was supported by the German Research Foundation (DFG grant DR772/12-1 to CD), the European Commission project PREPARE (contract number 602525) and the ZAPI project; IMI grant agreement $n^{\circ} 115760$, with the assistance and financial support of IMI and the European Commission, in kind contributions from EFPIA partners.

Disclaimer: The findings and conclusions in this report are those of the authors and do not necessarily represent the official position of the U.S. Centers for Diseases Control and Prevention.

Authors' addresses: Peninah Munyua and Marc-Alain Widdowson, Global Disease Detection Program, Division of Global Health Protection, U.S. Centers for Disease Control and Prevention, Nairobi, Kenya, E-mails: ikg2@cdc.gov and zux5@cdc.gov. Victor Max Corman and Christian Drosten, Institute of Virology, University of Bonn Medical Centre, Bonn, Germany, and German Centre for Infection Research, Partner Site Bonn-Cologne, Bonn, Germany,
E-mails: corman@virology-bonn.de and drosten@virology-bonn.de. Austine Bitek and Rees Murithi, State Department of Veterinary Services, Ministry of Agriculture Livestock and Fisheries, Nairobi, Kenya, E-mails: bitekorinde@gmail.com and murithi.mbabu@gmail.com. Eric Osoro, Department of Preventive and Promotive Health, Ministry of Health, Nairobi, Kenya, E-mail: osoroe@gmail.com. Benjamin Meyer and Marcel A. Müller, Institute of Virology, University of Bonn Medical Centre, Bonn, Germany, E-mails: meyer@virologybonn.de and muller@virology-bonn.de. Erik Lattwein, EUROIMMUN AG, Lübeck, Germany, E-mail: e.lattwein@euroimmun.de. S. M. Thumbi and $M$. Kariuki Njenga, Center for Global Health Research, Kenya Medical Research Institute, Nairobi, Kenya, and Paul G. Allen School for Global Animal Health, Washington State University, Pullman, WA, E-mails: thumbi.mwangi@wsu.edu and knjenga@vetmed.wsu.edu.

This is an open-access article distributed under the terms of the Creative Commons Attribution License, which permits unrestricted use, distribution, and reproduction in any medium, provided the original author and source are credited.

\section{REFERENCES}

1. World Health Organization (WHO), 2016. Middle East Respiratory Syndrome Coronavirus. Available at: http://www.who.int/ emergencies/mers-cov/en/. Accessed June 22, 2016.

2. Alsahafi AJ, Cheng AC, 2016. The epidemiology of Middle East respiratory syndrome coronavirus in the Kingdom of Saudi Arabia, 2012-2015. Int J Infect Dis 45: 1-4.

3. Hunter JC, Nguyen D, Aden B, Al Bandar Z, Al Dhaheri W, Abu Elkheir K, Khudair A, Al Mulla M, El Saleh F, Imambaccus H, Al Kaabi N, Sheikh FA, Sasse J, Turner A, Abdel Wareth L, Weber S, Al Ameri A, Abu Amer W, Alami NN, Bunga S, Haynes LM, Hall AJ, Kallen AJ, Kuhar D, Pham H, Pringle K, Tong S, Whitaker BL, Gerber SI, Al Hosani FI, 2016. Transmission of Middle East respiratory syndrome coronavirus 
infections in healthcare settings, Abu Dhabi. Emerg Infect Dis 22: 647-656.

4. Liu S, Chan TC, Chu YT, Wu JT, Geng X, Zhao N, Cheng W, Chen E, King CC, 2016. Comparative epidemiology of human infections with Middle East respiratory syndrome and severe acute respiratory syndrome coronaviruses among healthcare personnel. PLoS One 11: e0149988.

5. Haagmans BL, Al Dhahiry SH, Reusken CB, Raj VS, Galiano M, Myers R, Godeke GJ, Jonges M, Farag E, Diab A, Ghobashy $\mathrm{H}$, Alhajri $\mathrm{F}$, Al-Thani M, Al-Marri SA, Al Romaihi HE, Al Khal A, Bermingham A, Osterhaus AD, AlHajri MM, Koopmans MP, 2014. Middle East respiratory syndrome coronavirus in dromedary camels: an outbreak investigation. Lancet Infect Dis 14: 140-145.

6. Memish ZA, Cotten M, Meyer B, Watson SJ, Alsahafi AJ, Al Rabeeah AA, Corman VM, Sieberg A, Makhdoom HQ, Assiri A, Al Masri M, Aldabbagh S, Bosch BJ, Beer M, Muller MA, Kellam P, Drosten C, 2014. Human infection with MERS coronavirus after exposure to infected camels, Saudi Arabia, 2013. Emerg Infect Dis 20: 1012-1015.

7. Nowotny N, Kolodziejek J, 2014. Middle East respiratory syndrome coronavirus (MERS-CoV) in dromedary camels, Oman, 2013. Euro Surveill 19: 20781.

8. Corman VM, Jores J, Meyer B, Younan M, Liljander A, Said MY, Gluecks I, Lattwein E, Bosch BJ, Drexler JF, Bornstein S, Drosten C, Muller MA, 2014. Antibodies against MERS coronavirus in dromedary camels, Kenya, 1992-2013. Emerg Infect Dis 20: 1319-1322.

9. Deem SL, Fevre EM, Kinnaird M, Browne AS, Muloi D, Godeke GJ, Koopmans M, Reusken CB, 2015. Serological evidence of MERS-CoV antibodies in dromedary camels (Camelus dromedaries) in Laikipia County, Kenya. PLoS One 10: e0140125.

10. Meyer B, Muller MA, Corman VM, Reusken CB, Ritz D, Godeke GJ, Lattwein E, Kallies S, Siemens A, van Beek J, Drexler JF, Muth D, Bosch BJ, Wernery U, Koopmans MP, Wernery R, Drosten C, 2014. Antibodies against MERS coronavirus in dromedary camels, United Arab Emirates, 2003 and 2013. Emerg Infect Dis 20: 552-559.

11. Muller MA, Corman VM, Jores J, Meyer B, Younan M, Liljander A, Bosch BJ, Lattwein E, Hilali M, Musa BE, Bornstein S, Drosten C, 2014. MERS coronavirus neutralizing antibodies in camels, eastern Africa, 1983-1997. Emerg Infect Dis 20: 2093-2095.

12. Chu DK, Oladipo JO, Perera RA, Kuranga SA, Chan SM, Poon LL, Peiris M, 2015. Middle East respiratory syndrome coronavirus (MERS-CoV) in dromedary camels in Nigeria, 2015. Euro Surveill 20: 11-17.

13. Gutierrez C, Tejedor-Junco MT, Gonzalez M, Lattwein E, Renneker S, 2015. Presence of antibodies but no evidence for circulation of MERS-CoV in dromedaries on the Canary Islands, 2015. Euro Surveill 20: 31-34.

14. Hemida MG, Chu DK, Poon LL, Perera RA, Alhammadi MA, Ng HY, Siu LY, Guan Y, Alnaeem A, Peiris M, 2014. MERS coronavirus in dromedary camel herd, Saudi Arabia. Emerg Infect Dis 20: $1231-1234$.

15. Crameri G, Durr PA, Barr J, Yu M, Graham K, Williams OJ, Kayali G, Smith D, Peiris M, Mackenzie JS, Wang L-F, 2015. Absence of MERS-CoV antibodies in feral camels in Australia: implications for the pathogen's origin and spread. One Health 1: 76-82.

16. Hemida MG, Perera RA, Al Jassim RA, Kayali G, Siu LY, Wang P, Chu KW, Perlman S, Ali MA, Alnaeem A, Guan Y, Poon LL, Saif L, Peiris M, 2014. Seroepidemiology of Middle East respiratory syndrome (MERS) coronavirus in Saudi Arabia (1993) and Australia (2014) and characterisation of assay specificity. Euro Surveill 19: 2-7.

17. Muller MA, Meyer B, Corman VM, Al-Masri M, Turkestani A, Ritz D, Sieberg A, Aldabbagh S, Bosch BJ, Lattwein E, Alhakeem RF, Assiri AM, Albarrak AM, Al-Shangiti AM, Al-Tawfiq JA, Wikramaratna P, Alrabeeah AA, Drosten C, Memish ZA, 2015. Presence of Middle East respiratory syndrome coronavirus antibodies in Saudi Arabia: a nation- wide, cross-sectional, serological study. Lancet Infect Dis 15: 629.

18. Food and Agriculture Organization (FAO), 2001. FAOSTAT Database, 2001. FAO, ed. Available at: http://www.fao.org/faostat/ en/data/QA/visualize. Accessed January 1, 2016.

19. Abroug F, Slim A, Ouanes-Besbes L, Hadj Kacem MA, Dachraoui F, Ouanes I, Lu X, Tao Y, Paden C, Caidi H, Miao C, Al-Hajri MM, Zorraga M, Ghaouar W, BenSalah A, Gerber SI; World Health Organization Global Outbreak Alert and Response Network Middle East Respiratory Syndrome Coronavirus International Investigation Team, 2014. Family cluster of Middle East respiratory syndrome coronavirus infections, Tunisia, 2013. Emerg Infect Dis 20: 1527-1530.

20. Liljander A, Meyer B, Jores J, Muller MA, Lattwein E, Njeru I, Bett B, Drosten C, Corman VM, 2016. MERS-CoV antibodies in humans, Africa, 2013-2014. Emerg Infect Dis 22: 1086-1089.

21. Osoro EM, Munyua $P$, Omulo S, Ogola E, Ade F, Mbatha $P$, Mbabu M, Ng'ang'a Z, Kairu S, Maritim M, Thumbi SM, Bitek A, Gaichugi S, Rubin C, Njenga K, Guerra M, 2015. Strong association between human and animal Brucella seropositivity in a linked study in Kenya, 2012-2013. Am J Trop Med Hyg 93: 224-231.

22. World Health Organization (WHO), 2015. Laboratory Testing for Middle East Respiratory Syndrome Coronavirus (MERS-CoV) Interim Guidance. Available at: http://apps.who.int/iris/bitstream/ 10665/176982/1/WHO_MERS_LAB_15.1_eng.pdf?ua=1. Accessed June 22, 2016.

23. Muller MA, Meyer B, Corman VM, Al-Masri M, Turkestani A, Ritz D, Sieberg A, Aldabbagh S, Bosch BJ, Lattwein E, Alhakeem RF, Assiri AM, Albarrak AM, Al-Shangiti AM, Al-Tawfiq JA, Wikramaratna P, Alrabeeah AA, Drosten C, Memish ZA, 2015. Presence of Middle East respiratory syndrome coronavirus antibodies in Saudi Arabia: a nationwide, cross-sectional, serological study. Lancet Infect Dis 15: 559-564.

24. Park SW, Perera RA, Choe PG, Lau EH, Choi SJ, Chun JY, Oh $\mathrm{HS}$, Song KH, Bang JH, Kim ES, Kim HB, Park WB, Kim NJ, Poon LL, Peiris M, Oh MD, 2015. Comparison of serological assays in human Middle East respiratory syndrome (MERS)coronavirus infection. Euro Surveill 20: 13-17.

25. Reusken CB, Farag EA, Jonges M, Godeke GJ, El-Sayed AM, Pas SD, Raj VS, Mohran KA, Moussa HA, Ghobashy H, Alhajri F, Ibrahim AK, Bosch BJ, Pasha SK, Al-Romaihi $\mathrm{HE}, \mathrm{Al}-\mathrm{Thani} \mathrm{M}$, Al-Marri SA, AlHajri MM, Haagmans BL, Koopmans MP, 2014. Middle East respiratory syndrome coronavirus (MERS-CoV) RNA and neutralising antibodies in milk collected according to local customs from dromedary camels, Qatar, April 2014. Euro Surveill 19: 8-12.

26. Al Hammadi ZM, Chu DK, Eltahir YM, Al Hosani F, Al Mulla M, Tarnini W, Hall AJ, Perera RA, Abdelkhalek MM, Peiris JS, Al Muhairi SS, Poon LL, 2015. Asymptomatic MERS-CoV infection in humans possibly linked to infected dromedaries imported from Oman to United Arab Emirates, May 2015. Emerg Infect Dis 21: 2197-2200.

27. Alshukairi AN, Khalid I, Ahmed WA, Dada AM, Bayumi DT, Malic LS, Althawadi S, Ignacio K, Alsalmi HS, Al-Abdely HM, Wali GY, Qushmaq IA, Alraddadi BM, Perlman S, 2016. Antibody response and disease severity in healthcare worker MERS survivors. Emerg Infect Dis 22: 1113-1115.

28. Gossner C, Danielson N, Gervelmeyer A, Berthe F, Faye B, Kaasik Aaslav K, Adlhoch C, Zeller H, Penttinen P, Coulombier D, 2016. Human-dromedary camel interactions and the risk of acquiring zoonotic Middle East respiratory syndrome coronavirus infection. Zoonoses Public Health 63: 1-9.

29. Reeves T, Samy AM, Peterson AT, 2015. MERS-CoV geography and ecology in the Middle East: analyses of reported camel exposures and a preliminary risk map. BMC Res Notes 8: 801.

30. Faye B, 2013. Camel farming sustainability: the challenges of the camel farming system in the XXIth century. J Sustain Dev 6: 74-82. 